\title{
The Blooming of Forgetting: Deep Play as a Focus for Improvisation in Community Music
}

\author{
Paddy Gordon \\ The universe wants to play... \\ Hakim Bey, Temporary Autonomous Zones
}

\section{Background}

The musician Conor O'Hanlon and I facilitated two iterations of a community music project grounded in improvisation in Melbourne, Australia in 2016. Called "Our Community Sounds," the first set of workshops took place at the Testing Grounds art-space (http://www.testing-grounds.com.au), a site dedicated to the emerging, the experimental, and the ad hoc, located appropriately behind Melbourne's mainstream arts precinct. These workshops/sessions/experimental community arts events ran roughly monthly. This schedule proved to be somewhat of a weakness in terms of consistent attendance and building a cohesive group, although it did allow us the freedom to deploy very different techniques at each session. We ran our second set of workshops consecutively over five weeks at the Body Voice Centre in Footscray (http://www.bodyvoice.com.au), a venue as suited to yoga classes as it is to projects such as ours. Additionally, Footscray is probably Melbourne's most multicultural suburb, and is home to many intersections of cultural and linguistic diversity. We were able to build a more cohesive group at this second set of sessions, and as such we focused more on honing a handful of techniques, specifically developing processes and approaches first explored at Testing Grounds.

The methods we used throughout the sessions evolved subtly, and we worked in a way that intertwined theory and practice: testing out various things and retaining and developing what worked whilst discarding or bracketing for future development what didn't. We started by posing some simple questions: How best to create conditions to meaningfully explore improvisation in community arts settings? How best to encourage participation in such improvisation by people who may start sessions as strangers to each other? How best to work with changing combinations of non-musicians and musicians, and people of different ages and abilities, in such a dynamic, unpredictable context? How to help participants feel safe whilst experiencing a certain necessary ontological discomfort? And if "deep play" represents a powerful and empowering means of addressing and progressing all of these questions, how do we define, locate, and encourage deep play?

Our own work as facilitators/leaders was also constantly under investigation: we assessed this work in our own discussions and by soliciting feedback from each group. At each workshop, we tried to progress gradually (ideally almost imperceptibly) from basic warm-up exercises to very free improvisation. However, we also saw value in "parachuting in" potentially radical improvisational approaches, especially in early workshops, and seeing how both individuals and the group responded to these without preparation or warning. By the time we had refined our processes (around weeks two to three of the second set of sessions), we had a pattern we generally followed, starting with stretching and simple vocal warm ups. We then proceeded to call and response games (often using the names of participants as musical material), followed by clapping simple interlocking rhythms. We might then try making unusual noises and gestures as a means of quickly moving outside of what might be considered conventionally musical, as well as inviting participants to "throw away" sounds, snatches of songs, melodies, or rhythms that they had stuck in their heads by singing them out loud, often accompanied by flinging or purging gestures. We'd then take turns to make a sonic gesture which was repeated or varied by each participant, sometimes within strict parameters, sometimes however they saw fit. After this stage, we found that an alteration between very free and what we denoted "authoritarian" approaches was usually productive-first using a modified version of Rully Shabara's Raung Jagat vocal improvisation technique,$^{1}$ then immediately following this up with naming a mood or scene that we wanted participants to set and giving them no further instructions other than a certain time frame in which to set it. This was usually the first time that musical instruments were used. We then encouraged participants to swap instruments or try an instrument they had never played before, before we concluded with a group free improvisation. These last few stages were considerably longer than the warm-ups. All the while we were observing and interacting with participants, making constant micro-assessments as to whether a particular development should be encouraged or challenged.

Despite all this, I hope and trust that we resisted treating these sessions as too much of a laboratory. First and foremost this is community music, and ultimately our aesthetic values (with the corollary of these being a desire to use avant-garde ideas, approaches and techniques) must be secondary to outcomes of connection and communion for whoever has assembled for each session. Of course, these outcomes can be pretty nebulous. Conor and I were relatively new to this, although l'd recently completed some postgraduate studies in arts and community engagement, 
and Conor has been involved in community arts for some time, both as participant and facilitator. We'd also previously worked with refugee groups in Melbourne, and have long been performers of experimental and improvised music. The aim then—broadly_was for participants in each session to walk away feeling like they'd been able to genuinely connect with others and express themselves. This outcome also implies a method of modelling participation in positive and empowering communities: if making some interesting art is part of this then that's a bonus. Ideally, of course, we're looking for a deep intertwining of both, a profound and subtle entanglement that erases the dichotomy just posited between community and aesthetic values.

\section{Assessment of the Projects}

How then is one to measure the success_or otherwise-of a community-music improvisation project? Improvisation surely implies a certain intangibility, an ultimate impenetrability to theory and taxonomies. Indeed, as Derek Bailey notes, "improvisation is always changing and adjusting, never fixed, too elusive for analysis and precise description ... any attempt to describe improvisation must be, in some respects, a misrepresentation" (Bailey ix). Community likewise is a complex concept. We were working from a certain idealisation of community, positing and testing the possibility of an assemblage wherein each participant has a shifting but tangible stake, and a means of making what feels for them a meaningful contribution. Our idea of community was fundamentally concerned with relationality, where we are bound not by geography or identity but by what we might be able to explore and establish together; following Massumi and Manning in seeking to enter a radical ontological space that might reveal at each instant $a$ "positive expression of how everything in the field, moving and still, integrally relates at that instant ... the appearance of the field's relationality" (9). Considering community along such lines allows us to move past impasses that geography or identity might impose, to circumvent constitutive constraints that limit at the outset our expressive and ontological possibilities.

Of course this idea of community can and should be problematised. We can do this by bearing in mind Martin Heidegger's "the they": how the being of others and their (our) social norms, conventions and means of expression lead each individual away from their ultimate potential for authenticity, and how our "ownmost possibility (death) is non-relational" (308). We are all part of a "they" as well, however. Complex entanglements of individual and group subjectivity will always be a factor in community music improvisation, and we perhaps need to accept that 'authentic' individual expression must necessarily be sacrificed to some degree in this context. We will do well also to remember not to idealise the results of sessions like ours-both musical and otherwise-as the fullest possible manifestation of each individual's capacity for expression blooming side-by-side into a group ontology that is somehow grounding, empowering, and transcendent. Community is a compromise, as group improvisation must also be.

It seems, therefore, that a community-improv project presents a subjective-group ${ }^{2}$ experience, where what happens is not explicable from merely one point of view; indeed, one point of view may not even be a locatable viewpoint in the kind of situation we are discussing. When the group is immersed in the moment, and the shared ideas that arise are developed according to the enmeshing of the psyches that produced each preceding moment and must be responsible also for the moments to come: how can the thing that is at each moment not slip from our grasp? Certainly theory -in the sense of explanations for how and why certain things happen at certain times and in certain ways - seems too blunt an instrument to circumscribe such a subtle thing. As such external measurements seem like the wrong way to proceed, as whatever can be grasped by them will present only a hollow shell or a lonely adumbration, and the essence will slip from our grasp as surely as music moves from one moment to the next. We must be careful here, however, not to valorize, or perhaps even reify, a coming together that necessarily generates both ineffably interesting music and a synchronous ontological realignment, heeding Massumi and Manning's warning that "a purely consensual process deadens potential . . . irruptions of decision are necessary for the vitality of a creative process" (104). It was obvious to us from a very early stage that "just letting things flow" was not enough: "as if simply unconstrained interaction were sufficient to enable something 'creative' to happen" (93). We need to guard against thinking that merely a cohesive group playing freely with each other will automatically yield innovative music or community connectivity. Likewise, it's too simple to say that we have in the improvised moment a pure qualitative experience that necessarily resists any attempt to describe or analyze: this claim merely enhances the unhelpful binary already existent between the free/musical/creative and the rigid/theoretical/analytic. ${ }^{3}$ Thinking along such lines leads us into territory that's already over-explored; I don't want to challenge or break down such distinctions so much as see if they can be productively ignored. Nevertheless, it is undeniable that in community-music improvisation we're seeking to lead participants into a space that is largely held together by alongsideness, connectivity, and consensus: that is about creating more so than analyzing, exploring free play rather than encouraging adherence to prior habituations and education or routine cognitive structures. As such, might we not have unearthed here a (unit of) measure for the success (or otherwise) of any particular iteration of such a project? If we seek to enable free-and deep_play, to see participants joyfully and surely break with (and potentially reassemble) their accumulated knowledge, education, and inhibiting conventional baggage, musical and otherwise, isn't it the case that the more instances of such play and such breaks we can locate, the better the whole thing is going? Let's grasp on to this 
concept of play. We've seen by now that this is particularly slippery terrain, and that one could proceed almost indefinitely in all directions at once, a paradoxical stasis of the ungraspable-but I think for the sake of a productive discussion it might be time to pretend we can hold on for a little while.

So with deep play we have a means by which we can perhaps measure the success of our project, or at least point to instances where things were going well. But what exactly is deep play? How will we know it when we meet it?

The anthropologist Clifford Geertz provides the classic definition, and indeed there are many elements of his thinking on the subject that resonate here. If deep play is constituted by "a set of persons engaged in a common flow and relating to each other in terms of that flow" (Geertz 65), then we can agree with Geertz's definition. However, deep play in the sense that he explores it is also about all those involved in such play being "in over their heads" as they "activate ... rivalries and hostilities, but in 'play' form" (77). From this perspective our instinct might be to immediately engage with the depth of immersion of participants and be more circumspect as regards the symbolic dimension. A demanding question is opened here, however: how can we ensure the play is really deep when there is not so much at stake? In Geertz's example of the Balinese Cockfight, the deepest matches are between individuals of equally high status, where one's social position is at symbolic risk. How could a community music improvisation present the same stakes? If we probe a little, however, we see that in seeking to activate spaces of deep play, the stakes can be very high indeed. Partly what constitutes our own idea of deep play is a certain (obviously unquantifiable) level of immersion. If we view this through the lens of Pauline Oliveros's deep listening, which differentiates mere hearing from actively listening, and involves "learning to expand the perception of sounds" so that "new fields of thought can be opened and the individual may be expanded and find opportunity to connect in new ways to communities of interest" (Oliveros xxiii-xxv) we can see that it also involves taking responsibility, both individually and collectively; this points to a decisive voluntary engagement with the group, as well as joint responsibility for its sound world or acoustic ecology. Taking responsibility is an empowering means of community participation, often neglected or even discouraged at the level of ontology under our current neoliberal paradigm.

Deep play also means we are profoundly immersed in our music and the processes that we are using to discover and make it. As such, we can see how deep play might enable the subsuming of individual consciousnesses into the subjective-group. Deep play (traced via deep listening) therefore both helps and encourages us to value the participation of all group members: musicians, nonmusicians and people of different ages, abilities, and backgrounds. It also enables meaningful engagement-the opportunity for each participant to make a purposeful and decisive contribution-as potentialities for new sounds and ways of coming together bloom from this immersive approach. As Geertz describes the "migration of the Balinese status hierarchy into the body of the cockfight" (73), can we not also project a level of relationality and communion, a radical interrogation and reevaluation at the very level of (both individual and group) ontology, when we engage in deep play together? Here we have a powerful method of modelling community: like Hakim Bey's temporary autonomous zones, deep play might "expand until it infects or becomes the social" (Bey 2011), at least for our temporary communities. For Geertz deep play involves playing with how things already are, and the purpose of such play is to temporarily animate what is static: nothing really changes; "the cockfight is only 'really real' to the cocks" (Geertz 79). For us, deep play is fundamentally dynamic. We all have a stake in creating, exploring, and modelling what might be.

Can we be certain we'll always get there? Can we locate and collate moments where participants are in this kind of zone? We can't; at least, not definitively. We have to trust our instincts, and follow them over beyond where our knowledge and education might stop, beyond where we can categorise with certainty. Perhaps we can sense a parallel to the engagement with our project that might deliver an adult over to the realms of deep play: gradually and quasi-empirically testing gestures and moves until one establishes a certain alignment and fusion, a confidence that enables a radical schism; and then all of a sudden the unknown presents not as a void into which one might tumble, a disorienting and anxiety-bound severing of convention, but rather a blooming space of childlike wonder and delight, where in each instance we can make and remake without conventions that initiate foreclosures of possibility, knowing without knowing that we will always respond appropriately because we are always responding intuitively. This is true play: free and deep.

Some examples? I think back to the third session of our first project, at Testing Grounds, where Robert, an elderly and shy classically-trained pianist, joyfully played a dilapidated piano with his arse. Also the instance where one facilitator abandoned any attempt to facilitate and rather upended a metal 'bin-drum', placing same on his head and thwacking it with a sturdy stick - concussion and percussion simultaneously, perhaps. The moments (some longer than others, but admittedly none too long) during the free improv sections of our sessions at the Body Voice Centre where what might be denoted 'subjective-group irruptions' occurred: temporary zones of consensus where each member of the group roved freely round the space, interacting with each other as they encountered each other, only to resume atomisation when each gestural exchange/interplay was exhausted. What never seemed exhausted, however, was a sort of reserve from which the very possibility of gesture-and gestural possibilities-sprung. It was 
hard to predict when this reserve might be tapped, but a certain charge-a field of possibilities-seemed latent in each session. I would venture that each different assemblage of participants creates a unique subjective-group reserve, various potential arrangements of community.

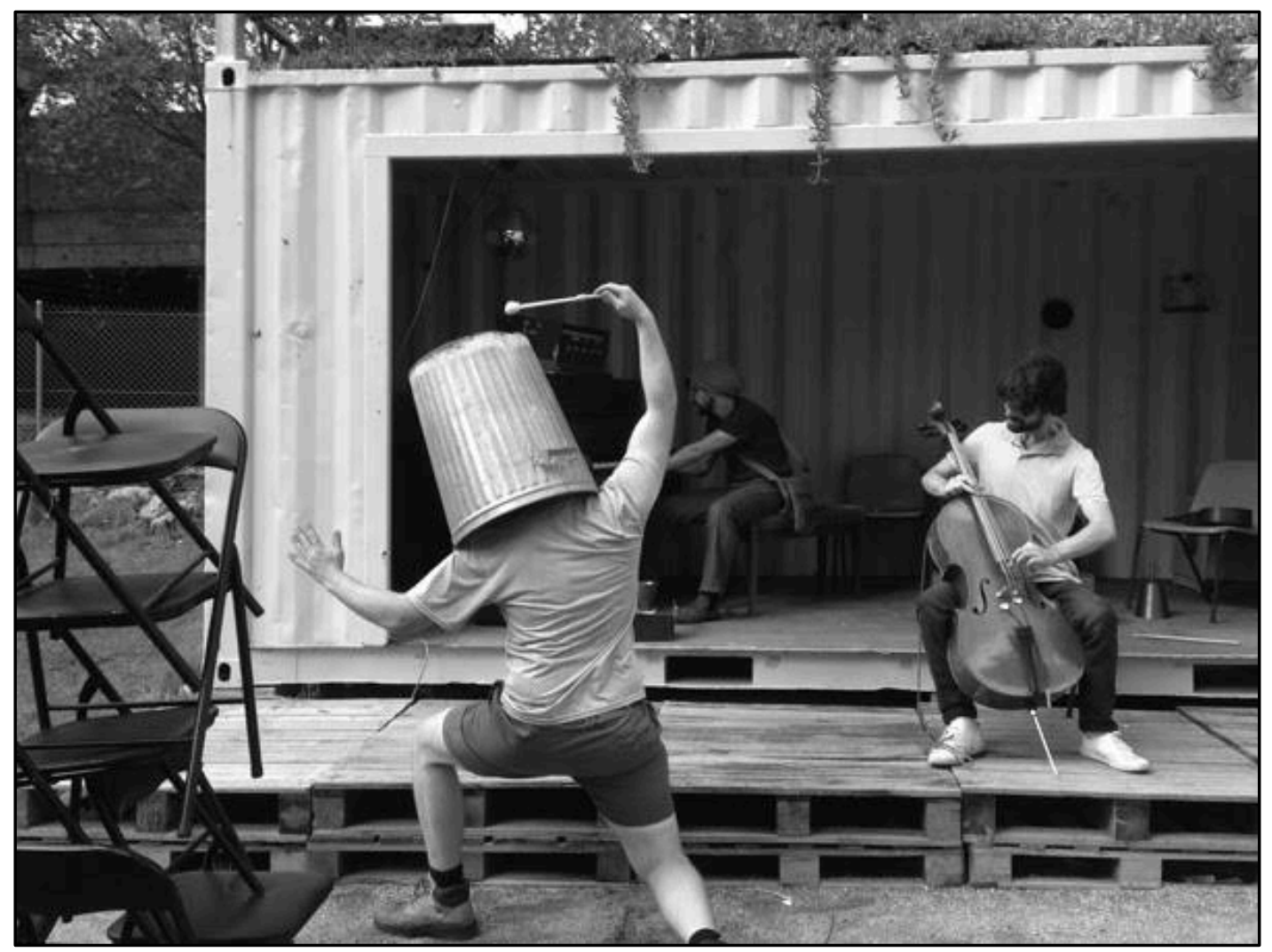

Deep-play in progress? Facilitators Conor O'Hanlon (with bin-drum on head) and Paddy Gordon (with cello). Photo credit: Sam Quinlan.

Coterminous with this field or charge were so many moments of the behaviour and play of children: there's really something in this, I think. As soon as children that attended were coaxed out of shyness and into contributing, almost inevitably we could observe a sense of deep and serious engagement with the space's acoustic ecology, a real utilisation of whatever was to hand to create and share sonic gestures. Adults, simply, are not so good at this. We have forgotten, and what is needed to help participants create on this level is a further forgetting, alluded to above as a willingness to attempt to go beyond-and productively forget-our knowledge, education and categorical certainties. l've seen enough along these lines to conclude that perhaps the most crucial role of the facilitator is to help with this process.

Heidegger's concept of the "ready-to-hand" is a useful theoretical tool to think about engagement with the world on this level. When Heidegger says "our concernful absorption in whatever work-world lies closest to us, has a function of discovering" (101), he points to a pre-theoretical level of engagement with our environment on which we naturally operate, but which is often obscured by theory and reflective cognition. "If we look at Things just 'theoretically', we can get along without understanding readiness-to-hand. But when we deal with them by using them and manipulating them, this activity is not a blind one; it has its own kind of sight. .." (Heidegger 98, italics mine). When children played seriously with and within the acoustic ecology of the space, their "concernful absorption" pointed to a vitality and depth that permeated and generated their play. Mightn't we posit something similar for adults? I think we saw this at times in our sessions, perhaps moreso early on, when participants played rocks and fences, improvised songs from bizarre vocal experiments, or played the piano as if it was a drum. If we seek new ontological potentialities that open up new ways to make sound - and new ways of making sound open new ontological potentialities-an initial forgetting or letting go will surely enable us to move towards the state of deep play, in which discoverable ontologies, relationalities and gestures are bound, and can be tested, activated and withdrawn. Deep play is an entanglement of the "for-the-sake-of," the "in-order-to" and the "towards-this" in Heideggerian terminology: how and what we use to move towards where and what we might be. Yet as soon as we make that move: there we are (or already were). The usefulness of forgetting for moving away from our usual ways of being is echoed by Heidegger when he says that "when something ready-to-hand is found missing . . . this makes a break in those referential contexts which 
circumspection discovers . . The environment announces itself afresh" (105). Could a break also be a forgetting, a letting go, except with the caveat that we choose consciously here to leave behind what is known, or at least enact a process that might enable this. Revealed here are both new possibilities for exploring our subjective-group being, as well as that which we necessarily have forgotten, what we use and engage with on a level deeper than active consciousness. Deep play therefore implies and supports a process of forgetting. The question that presents most profoundly for facilitators, then, is how to enable this process.

\section{Potential Methodologies to Enable 'Deep Play'}

The size and scope of what's opened up by the process of forgetting described above gives the first clue as to what some practical methods to use might be. Obviously there can be a certain grandiosity implied when we talk about ontological ruptures and reconceptions-obviously also, this isn't going to be what happens every time for every person. The facilitator's role is certainly not to push participants into a zone that demands abandonment, transgression and radical ontological interrogations; it isn't really to push at all. Even the model of 'leading by example' into radical spaces is somewhat problematic, as this imposes an ideal towards which each subjective-group should strive, where rather what we're looking for is a process of joint discovery, investigation, and experimentation, an alongsideness that points to the de-hierarchisation that exists in these moments of deep play. Such moments, however, are elastic, and might stagger and overwhelm with their grandeur or slip by in tiny lithe increments. We may even mistake these for each other.

Collapsing the big into the small might also mean conflating quasi-empirical gestural tests with immersion in deep play's abyss. If we are able to see the possibility for each moment and each gesture, regardless of the size or scope of these, to open up spaces for and of deep play, then the first move of the facilitator is to abstain from prescribing or excluding any move made within the subjective-group. A problem arises here, of course: can we really just accept anything, abandoning all discernment in the hope that one moment may ignite another until we have a conflagration? If this seems unrealistic, then we have a clash with our values of non-judgement and alongsideness. Clashes of values are always revealing, but in terms of what we're discussing here (how to actually make this stuff work) we may have just led ourselves into further intractability. It would be easy here to conflate this with the difficulty of talking about improvisation in community music at all, and to wryly resign ourselves to an ironic correspondence between the ultimate futility of theory and the problematic entanglements of our practical processes. However, I think we can do better than this. If we seek strategies, techniques and approaches to enable the ineffable, it seems increasingly that these need to be based upon facilitating letting go or forgetting rather than instructing the group, using pedagogical approaches or passing on information. So faced with the above impasse, we don't try to prise apart the theoretical and the practical in our work so as to establish a hierarchy of values and proceed absolutely from these. Rather, we accept at every point an inherent intertwining: of theory and practice; of non-judgement and discernment; of the practiced and the provisional. From here, we simply do each time the best we can to move alongside each other into a space where we might draw on anything in order to abandon everything, playing with a free and joyful rhizomatic abandon.

Deep play cannot be circumscribed, but by practicing letting go we can approach its ever porous perimeter, and then at any time we might fall. How we make approaches is of course heavily context-dependent, but might take many forms - approaches based on deep listening and meditation are potentially very useful here, and the exercises described at the start of this piece were certainly useful in loosening up participants, helping them to relax into discomfort and connect with one another. We might also contrast two methods of facilitating group improvisation as ways to approach deep play. Our modified and simplified form of Raung Jagat we denoted an authoritarian approach, in contrast to the more anarchic free improvisation. The difference in our facilitation was key here. In Raung Jagat, the sound of the group as a whole is directed and controlled by the facilitator, although individuals do have a degree of autonomy as to which sounds they make. But the facilitator can determine crucial elements such as duration, volume, and density or texture at both the individual and group level. In our totally free examples, we were ideally simply other contributors, as we worked towards a space of alongsideness. We might, of course, initiate gestures, thus setting parameters that are taken up unconsciously by participants, and we might encourage or discourage certain contributions by repetition, eye contact, or body language-ultimately, however, we sought to open the space and then dissolve into it. Raung Jagat similarly collapses the individual into the group, however, by engaging directly with each participant the facilitator also bestows upon each a degree of responsibility. As this is taken, the individual moves from announcing and developing their contribution to hearing and shaping it as part of the whole, and thus we have the combination of responsibility and subsumption that we encounter in moments of deep play. Group free improvisation works towards the same destination but by the opposite route; group sound emerges first, as individuals receive no definite direction, and thus every individual emanation in combination is necessarily what the group sound also is. This is productively destabilizing, as each participant is reminded of their individuality and must work towards connecting with others, which again implies a taking of responsibility. As a sonic repertoire and an overall sound world or acoustic ecology is established as shared amongst all participants, individuals then focus in on 
experimenting with their own contributions, noticing how these alter or reinforce the group's overall dynamic. Again, we find atomisation evolving into collaboration, with responsibility, cohesion, and new relational and ontological possibilities emerging and developing. Using these approaches gives us two strong and adaptable methods by which we might approach deep play. It's not so much the process as the result, however-where we get, not how we get there-although to this end processes must be adaptable, and as such may turn out at times to be ends in themselves. Whilst deep play is what we're looking to enable, it's not like we can just have participants follow us there. Nevertheless, we can surely agree that the more we as facilitators practice the non-judgement, reconception of convention and taking of responsibility that abound in deep play the better. However, this certainly doesn't imply an anything goes approach, or that we will have deep play as long as certain conditions are met: as alluded to above, we can never know for sure how to get 'there,' but if we know what inhibits us getting to such a place, a disciplined process of practicing letting go of (or forgetting) these inhibitions will surely be helpful. As such, both Raung Jagat and facilitating free improvisation can be cultivated as practices that support us in forgetting, as we encounter radically new musical situations that move us outside of our ossified reserves of gestural potential. We can then try out new gestures and moves in new combinations, just as we discover that as individuals we are coming together in new ways.

Being able to improvise and adapt gently but decisively are therefore the key skills of the facilitator. Adapting processes and techniques on the run and on the ground; rejecting nothing initially and encouraging subjective-group non-judgement and alongsideness; establishing an environment that encourages and supports each participant in taking responsibility for their own gestures as well as for the sonic health of the group; keeping open opportunities to follow each line of expression, and adhering to these without establishing any absolute or definitive codification of the myriad permutations and sedimentations of each; curating a space that creates conditions for productive forgetting: this adds up to our methodology.

For now. Over time we will come to learn more and more-as we deepen the knowledge we must be always prepared to cheerfully relinquish —what leads to that blooming space of deep play. I've spent a lot of words trying to circumscribe it, only to conclude that we cannot really speak of it but must simply practice approaching it. We do know surely and deeply, though, when we are therein.

\section{Notes}

1 Raung Jagat is a method of improvised vocal music developed by the master Indonesian experimental musician Rully Shabara (Senyawa - https://senyawa.bandcamp.com/ and Zoo - https://soundcloud.com/zooindonesia). In Raung Jagat, which translates as 'the roar of the universe,' "the focus is to explore sounds of human voice, but at the same time 'force' people to create experimental music, boost confidence, appreciate sound, and learn the process of spontaneous music creation" (http://footscrayarts.com/cms/wpcontent/uploads/2016/02/FOLA_FCAC_EVENT_PR_RAUNG-JAGAT.pdf 2016). Conor participated in a three-day Raung Jagat workshop at Footscray Community Arts Centre in March 2016, and he and I used elements of the technique throughout our own series of workshops. This approach involved directing (by pointing/conducting) participants to make sounds of various qualities, durations, and intensities, and controlling the volume and blending of these_-treating the group as one giant dynamic instrument that could be controlled at the level of each individual and as a whole. This is a simple and powerful means of facilitating group improvisations, with potentially very sophisticated results. When Raung Jagat is mentioned in this piece, it is to the modified and simplified version we adapted that I refer. Both Conor and I are extremely grateful to Rully for demonstrating and allowing us to work with his method, and we were very fortunate to have him lead a Raung Jagat session at one of our workshops at the Body Voice Centre.

2 With the term 'subjective-group experience' I'm attempting to capture how a community-music improvisation actually proceeds for participants, how participation actually works, which is as a process of various degrees of merger of individual consciousnesses into a group composed of every subject present. Via this inherent inter-subjectivity, we end up ontologically with a temporary dual subject who, by participating in the music, demonstrates both their individuality and uniqueness and also their necessary engulfment by or subsumption in the group.

${ }^{3}$ Further development along these lines is beyond the scope of this piece, but an illuminating paragraph from a New Yorker interview with the pianist Vijay lyer occurred to me as pertinent here: "Improvising musicians are often taught to rid their minds of thoughts, which lyer regards as 'an impoverished view of thought.' George Lewis said, 'I'm suspicious of people who say they blank their minds to play. With Vijay, I think he's looking at the situation and making small tests. He's being careful and deliberative, even in the most ecstatic moments, which I find attractive. The ones who blank their minds, I'm always thinking, how can we get your attention? Someone who can operate like Vijay, on multiple levels of consciousness, that's what I admire'" (Wilkinson 26). 


\section{Works Cited}

Bailey, Derek. Improvisation: Its Nature and Practice in Music. Da Capo, 1993.

Bey, Hakim. "The Power of Art and the TAZ." Psychedelic Salon, podcast 293, December 2011, https://psychedelicsalon.com/category/people/hakim-bey/. Accessed 20 Nov. 2017.

"Festival of Live Art." Footscray Community Arts Centre, http://footscrayarts.com/cms/wcontent/uploads/2016/02/FOLA_FCAC_EVENT_PR_RAUNG-JAGAT.pdf. Accessed 20 November 2017.

Geertz, Clifford. “Deep Play: Notes on the Balinese Cockfight.” Daedalus, vol. 134, no. 4, 2005, pp. 56-86.

Heidegger, Martin. Being and Time. 1927. Translated by John Macquarrie and Edward Robinson, Harper Collins, 2008.

Massumi, Brian, and Erin Manning. Thought in the Act: Passages in the Ecology of Experience. U of Minnesota P, 2014.

Oliveros, Pauline. Deep Listening: A Composer's Sound Practice. iUniverse, 2005.

Wilkinson, Alec. "Time is a Ghost." The New Yorker, 1 Feb. 2016, pp. 22-8. 